Running head: EXTERNAL STRATEGIES AND INTERTEXTUAL PROCESSING

Comprehension of Relations among Controversial Texts:

Effects of External Strategy Use

Keiichi Kobayashi

Shizuoka University, Japan

Address: Faculty of Education, Shizuoka University, Shizuoka, 422-8529, JAPAN.

E-mail: ekkobay@ipc.shizuoka.ac.jp

Tel \& Fax: +81 0542384709 


\begin{abstract}
This study examined the effects of external strategy use on the comprehension of relations among controversial texts. Eighty undergraduates read 6 controversial texts for the purpose of either finding intertextual relations or forming one's opinion about the controversial issue. Half of them were permitted to use external strategies; the other half were not. Results indicated that only when given a purpose of relation-finding, external strategy users performed better than non-users in the comprehension of intertextual relations. Readers with a purpose of relation-finding also outperformed readers with a purpose of opinion-forming when permitted to use external strategies. The use of external strategies had no influence on the recall of intratextual arguments, regardless of reading purpose. These results were discussed in terms of readers' use of external strategies to serve their reading purposes.
\end{abstract}

Key words: controversial texts, external strategies, reading purposes, comprehension of intertextual relations, recall of intratextual arguments, undergraduate students. 


\section{Comprehension of Relations among Controversial Texts: \\ Effects of External Strategy Use}

Students in higher education are often required to read two or more controversial texts at a time. As a school assignment, for example, they may be demanded to read some articles that give different views on a controversial issue and then to write an essay on the issue (Bridgeman \& Carlson, 1984; Flower, Stein, Ackerman, Kantz, McCormick, \& Peck, 1990). This seems reasonable because democratic society is overflowing with controversial texts on a variety of issues, including social, political, economic, and scientific ones. It is important for students to become skilled in reading controversial texts.

In general, skilled reading of controversial texts involves understanding the intertextual relations. That is, readers must recognize that a controversy exists, find what the writers agree or disagree about, and identify each writer's position on the issue(s) in controversy (Britt, Perfetti, Sandak, \& Rouet, 1999; Rouet, Britt, Mason, \& Perfetti, 1996). Without a proper understanding of the intertextual relations, they may uncritically accept conflicting statements as true and make an unfair judgment on the controversial issue.

One likely factor that influences the comprehension of relations among controversial texts is the use of external strategies during reading. External strategies refer to cognitive operations that involve the production of external representations (Kobayashi, 2007a). They include all sorts of note-taking, annotating, and underlining/highlighting strategies. Researchers also use the terms overt responses (Todd \& Kessler, 1971), external learning strategies (Canelos, Dwyer, Taylor, \& Nichols, 1984), and complex study-reading strategies (Caverly, Orlando, \& Mullen, 2000). There is considerable evidence that under at least some conditions, external strategies are useful for executing a variety of cognitive tasks in academic situations: learning from a single text (Bretzing \& Kulhavy, 1979; Peverly, Brobst, 
Graham, \& Shaw, 2003), essay writing (Benton, Kiewra, Whitfill, \& Dennison, 1993; Kellogg, 1988), learning from a lecture (Kiewra, DuBois, Christian, McShane, Meyerhoffer, \& Roskelley, 1991; Pepper \& Mayer, 1986), and problem solving (Cary \& Carlson, 2001; Hegarty \& Steinhoff, 1997).

Evidence suggests that external strategies are in common use among readers of multiple texts (including controversial texts). Stahl, Hynd, Britton, McNish, and Bosquet (1996), for example, asked high school students to read five or six texts presented on a computer for the subsequent essay writing. Although they were not forced to do so, all the participants took notes. Sellen and Harper (2002) reported that professionals working in different fields (e.g., airline pilot, general surgeon, accounting assistant, marketing manager, social worker) were often engaged in taking notes, annotating, and highlighting as they read multiple texts at work.

Surprisingly, little is known about the role of external strategy use in the processing of controversial texts. One exception is a study by Britt and Sommer (2004, Experiment 1). It provided evidence suggesting that the use of external strategies during reading facilitates the intertextual processing. In their experiment, undergraduate students read two controversial texts one by one and then took post-tests. Half of them were told to write a brief summary of the first text before reading the second text; the other half were not. The result indicated that the summary group successfully integrated information across the two texts compared with the non-summary group, whereas the two groups did not significantly differ in the retention of information from each text. It should be noted, however, that Britt and Sommer were silent about the effects of summarizing strategy use on the comprehension of intertextual relations.

The purpose of the present study was to examine the effects of external strategy use on 
the processing of controversial texts. Specifically, I focused on the question of whether the use of external strategies during reading facilitates the comprehension of intertextual relations.

There are at least two possible ways in which the use of external strategies during reading contributes to the comprehension of intertextual relations. First, it may facilitate the intertextual processing through its effects on the intratextual processing. There is much evidence that the use of external strategies during reading stimulates deeper processing of a single text (see Caverly et al., 2000, for a review; Kobayashi, 2005, for a meta-analytic review). Although multiple-text reading is not mere multiple single-text readings, it requires processing information from each text (Lacroix, 1999; Rouet, 2006; Stahl et al., 1996). For example, readers of controversial texts must have a proper understanding of what individual writers said; otherwise they cannot recognize the relations among the writers' arguments accurately. It seems likely that the use of external strategies enhances the processing of individual texts, thereby making it easier to grasp the intertextual relations afterward. Second, a sheet of paper for notes can be used as a workplace where readers connect ideas across individual texts and represent the intertextual relations schematically. Prior research has shown that an effort to produce a structured external representation is often followed by the construction of a structured mental representation. In their study of single-text reading, for example, Kiewra, DuBois, Christian, Kim, and Lindberg (1989, Experiment 2) found that taking notes in a structured way helped the readers coordinate and integrate text information in their minds. The same may be applied to the external strategies that readers of controversial texts use for structuring information across the texts. In this case, the use of external strategies would have a direct influence on the comprehension of intertextual relations. 
The present study also examined whether reading orientation, or reading purpose given to students prior to reading, influences the effects of external strategy use. Probably the answer to this question is dependent on whether readers of controversial texts adjust their external strategies to serve the given reading purpose. Prior research has accumulated evidence that different types of external strategy stimulate different types of text processing (Bretzing \& Kulhavy, 1979; Kiewra et al., 1989; Lonka, Lindblom-Ylanne, \& Maury, 1994; see also Caverly et al., 2000, for a review). Thus, if readers differently use external strategies depending on their reading purposes, the effects of external strategy use would vary accordingly.

According to Caverly's et al. (2000) Demand model, skilled readers can tune their use of external strategies to the task demands. Unfortunately, the evidence as to whether that is so when students at higher schooling level read controversial texts is sparse and mixed. Stahl et al. (1996) asked high school students to read controversial texts on a historical event for the purpose of either forming their opinions about the topic or describing the historical event. They found no significant difference between the two groups in quality and quantity of notes produced. In contrast, Kobayashi (2007b) showed that when they read controversial texts, adult students adjusted their external strategies according to reading orientation. For example, readers who were given a purpose of describing the relations among the writers' arguments produced brief summaries of individual texts and intertextual notes (i.e., notes representing intertextual relations schematically) more than did those who were given a purpose of writing their opinions about the controversial issue, whereas the latter noted personal ideas (i.e., one's opinion, information from prior knowledge) more than did the former.

In the present study, participants read controversial texts for the purpose of either finding relations among the writers' arguments or forming their opinions about the 
controversial issue. To assess their use of external strategies, external representations that they produced during reading were analyzed. Given that readers adjusted their external strategies to fit the reading orientation, one could expect that the use of external strategies would be effective in the comprehension of intertextual relations when they were given a purpose of finding intertextual relations more than when given a purpose of forming their opinions.

\section{Method}

Participants and design

Eighty undergraduate students (25 males and 55 females) participated during a course of teaching methods at the Shizuoka University. Their ages ranged from 20 to 23 with a mean age of $20.93(S D=.62)$. They received extra course credit for their participation. The design was a $2 \times 2$ between-subjects factorial, with external strategy (use or non-use) and reading purpose (relation-finding or opinion-forming) as the factors. Participants were randomly assigned to one of the four conditions. There were 20 participants in each condition.

\section{Materials}

Texts. Six texts written in Japanese were selected from a reader's column in an evening edition of a Japanese newspaper, the Mainichi Shimbun (January 27, 2000). These texts were letters from six different readers who responded to an article, which had appeared in the same newspaper on January 11, 2000, on the introduction of English education into elementary schools in Japan. The brief summary of each text is presented in Table 1. The mean length of the texts was 305 letters $(S D=20.18)$ in Japanese. The texts, including each writer's name, age, and occupation, were printed in separate sheets of paper and presented simultaneously. 
Outcome measures. Outcome measures included two tasks: Intratextual-argument task and intertextual-relation task. Intratextual-argument task assessed participants' recall of what is argued in individual texts. It was used as an off-line measure of intratextual processing. Participants were told to recall each writer's argument and to write down it apart from the other writers' arguments. Intertextual-relation task tested participants' comprehension of intertextual relations. This task required them to describe how the six text-writers' arguments were interrelated with one another. While performing these tasks, participants were not allowed to refer to their notes and texts.

\section{Procedure}

According to their assigned condition, participants were given an envelope including either 6 printed texts and a sheet of white paper for notes (external strategy use group) or 6 printed texts only (non-use group). They were told to read the following instructions attached on the envelope:

"Now, you will read a set of six texts. Each text is a letter from a reader who responded to an article appeared in the Mainichi Shimbun on January 11, 2000. The article deals with the introduction of English education into elementary schools in Japan.”

Participants in the relation-finding groups were then told: "Read the texts and find the relations among the writers' arguments. You will receive some questions afterward.” The instructions to participants in the opinion-forming groups stated: "Read the texts and form your opinion about the introduction of English education into elementary schools in Japan. 
You will receive some questions afterward." Participants in each group were also divided in two: external strategy use group and non-use group. Participants in the external strategy use group were permitted to take notes, annotate, and underline while reading, whereas participants in the non-use group were not. I did not force the former group to use external strategies for two reasons. First, there is some evidence that study strategies are effective when used spontaneously more than when forced (Brown \& Smiley, 1978; Thornton, Bohlmeyer, Dickson, \& Kulhavy, 1990). Second, it was expected from prior findings (Kobayashi, 2007b; Stahl et al., 1996) that a large majority of students would spontaneously use external strategies while reading controversial texts. The time given to read was 20 minutes.

Following the reading time, all the texts and notes were removed and two tasks, intertextual-relation task and intratextual-argument task, were administered in that order. To complete these tasks, participants were given 25 minutes and 20 minutes respectively. At the end of the experiment, participants rated their familiarity with the topic using 5-point scale ranging from never (1) to very much (5).

Scoring

External strategies. Each participant's sheets of text and note paper were coded as present or absent for six categories: highlightings, discrete summaries, personal ideas, quasi-intertextual notes, miscellany of summaries, and intertextual notes. These categories were based on those used by Kobayashi (2007b). Highlightings refer to underlines, brackets, marks, or boxes that highlight a text portion (e.g., words, phrases, sentences). Discrete summaries are brief summaries of individual texts noted in the respective sheets of text paper. They are not explicitly related to each other. Personal ideas include evaluative comments, participants' opinions about the topic, or information from their prior knowledge. 
Quasi-intertextual notes refer to the marks (e.g., “○,” “×”) or words (e.g., “Approval," "Disapproval") noted in the respective sheets of text paper. Those marks and words indicate each writer's position on an issue common to two or more texts. Although this type of notes does not explicitly describe any intertextual relations, it presupposes processing across individual texts. Miscellany of summaries refers to the unstructured list of text-summaries. Individual text-summaries are written in a sheet of note paper but not related to each other. Intertextual notes refer to the information about individual texts (e.g., source information, text-summaries) of which relations are represented schematically in a sheet of note paper. A judge who was blind to the experimental conditions coded randomly selected $25 \%$ of the participants' sheets of text and note paper. Prior to the coding, the author fist explained the definitions of each category to the judge and then gave an opportunity to practice coding until interrater agreement reached an acceptable level. The percentage of agreement with the author was $98.3 \%$. A disagreement was due to that when coded a sheet of text paper, the judge mistook explanatory notes for discrete summaries. After a clarifying discussion, this disagreement was settled by consensus.

Intratextual-argument task. The participants' answers to the intratextual-argument task were scored in two ways: correct recall and incorrect recall. For the correct recall, the texts were segmented into 34 argumentative units. An argumentative unit was defined as a phrase (e.g., "In my long experience of teaching English to schoolchildren"), sentence (e.g., "True internationalization does not mean getting along well with other countries, but confidently expressing one's own views on various problems, including political and economic, pending between one's homeland and other countries.”), or set of sentences (e.g., “At international exchange programs for lower secondary schools, for example, Japanese students often look more immature than foreign students. They are so sensitive to their classmates' gaze that 
they cannot express their opinions with confidence. They consult with nearby classmates, obtain their consent, and finally express their opinions.") that makes a major claim or justification. This unit of analysis was employed because it includes the minimum essentials necessary for outlining each writer's overall argument, and because preliminary inspection of the data indicated that most of the participants' recall responses were a copy, paraphrase, or generalization of the text phrase or sentence(s) at this level. Credit was given for recall of an argumentative unit if the recall response for each text included the gist meaning of the original phrase or sentence(s). For the incorrect recall, the recall responses were segmented into sentences. A sentence was coded as incorrect if it was inconsistent with the gist meaning of any argumentative unit in a text or included argumentative unit(s) in the other texts. An independent judge was asked to code randomly selected $25 \%$ of the answers. Before the coding began, the judge was trained for the coding systems. The percentages of agreement with the author were $82.5 \%$ for the correct recall and $87.8 \%$ for the incorrect recall. Almost all the disagreements occurred because some of the recall responses were ambiguous and obscure. Disagreements were discussed and settled by consensus.

Intertextual-relation task. The answers produced by participants were segmented into statements that describe relations among two or more texts. A sentence or set of sentences was considered a description of intertextual relation if it included (a) what the writers agree or disagree about and each writer's position on the issue (e.g., "The two writers cast doubt on the necessity of becoming proficient in English.”), or alternatively, (b) similarities or differences among the attributes (e.g., age, gender, occupation) of the writers who agree or disagree about an issue (e.g., "The writers who approve early English education are all in their forties, whereas those who disapprove are in their thirties or seventies.”). Each statement was classified according to whether it described the intertextual relation in a valid 
way or not. A description of an intertextual relation was coded as valid if it was consistent with the writers' arguments and critical information (e.g., attributes of the writers) and as invalid if not. Examples of valid and invalid description of intertextual relations were presented in Appendix. An independent judge coded randomly selected 25\% of the answers after judge training. The percentage of agreement with the author was $84.8 \%$. Disagreements were mainly caused by the judge's failing to notice key information in the statements and/or poor descriptions of intertextual relations. The author and the judge traced the cause of each disagreement and settled it by discussion.

\section{Results}

\section{Familiarity rating}

The mean rating of familiarity was $3.36(S D=.92)$, indicating that most of the participants were familiar with the topic of the texts in greater or lesser degrees. A $2 \times 2$ analysis of variance (ANOVA), with external strategy and reading purpose as the between-subject variables, was performed on the familiarity rating. Neither main effects nor interaction were significant, all $F \mathbf{s}<1$. Preliminary analyses also revealed that this variable did not significantly relate to the use of external strategies and had no interaction effects with the recall of intratextual arguments and the comprehension of intertextual relations. Therefore, familiarity rating was not considered in the subsequent analyses.

\section{Use of external strategies}

Table 2 shows the number of participants in the external strategy group who produced each type of external representation. Fisher's exact test (one-tailed) was performed to examine the influence of reading purpose on the production of external representations. More participants in the relation-finding group produced intertextual notes $(p<.05)$ and discrete summaries $(p=.064)$ compared to participants in the opinion-forming group. On the 
other hand, more participants in the opinion-forming group produced personal ideas $(p<.05)$. There were no significant or marginally significant differences between groups for the number of participants who produced highlightings, quasi-intertextual notes, and miscellany of summaries.

Insert Table 2 about here

Recall of intratextual arguments

On average, participants recalled 10.49 argumentative units $(S D=4.39)$ correctly and 4.43 sentences $(S D=2.48)$ incorrectly. A $2 \times 2$ multivariate analysis of variance (MANOVA) was performed, with external strategy and reading purpose as the between-subject variables and the number of argumentative units recalled correctly and sentences recalled incorrectly as the dependent variables. The assumption of homogeneity was tenable, Box's $M=11.70$, $F(9,66192)=1.24, p>.26$. There were not significant main effects, $F \mathbf{s}<1$, or interaction, $F(2,75)=1.02, p>.36$.

\section{Comprehension of intertextual relations}

A $2 \times 2$ multivariate analysis of covariance (MANCOVA) was performed, with external strategy and reading purpose as the between-subject variables and the number of valid and invalid relations produced as the dependent variables. The covariates were correct and incorrect recall of intratextual arguments. The assumption of homogeneity was tenable, Box's $M=11.12, F(9,66192)=1.18, p>.30$. Of the two covariates, correct recall was significant, Hotelling's trace $=.18, F(2,73)=6.41, p<.005, \eta^{2}=.15$. Incorrect recall was marginally significant, Hotelling's trace $=.07, F(2,73)=2.53, p=.087, \eta^{2}=.07$. Main effects of external strategy and reading purpose did not reach significance, $F \mathrm{~s}<1$. However, 
there was a significant interaction between external strategy and reading purpose, Hotelling's trace $=.15, F(2,73)=5.46, p<.01, \eta^{2}=.13$.

The follow-up univariate analyses were performed with an alpha level of .025 , which was adjusted for Type I error using the Bonferroni method. There was a significant interaction effect for the number of valid relations produced, $F(1,74)=11.02, p<.005, \eta^{2}$ $=.13$. The interaction is shown in Figure 1. Planned comparisons $(p<.05)$ indicated that the external strategy use group produced valid relations (Adjusted $M=2.52$ ) significantly more than did the non-use group (Adjusted $M=1.14$ ) when given a purpose of finding relations among the texts. There was no significant difference between the two groups when given a purpose of forming their opinions (Adjusted $M=1.40$ and 1.94, respectively). Also, the relation-finding group produced valid relations significantly more than did the opinion-forming group when permitted to use external strategies, whereas no significant difference was found when not permitted to use external strategies. The interaction effect was not significant for the number of invalid relations produced, $F(1,74)=1.71, p>.19$.

Insert Figure 1 about here

\section{Discussion}

The present study addressed questions of whether the use of external strategies during reading facilitates the comprehension of relations among controversial texts, and if so, whether the effects of external strategy use differ according to reading purpose. The results indicated that when given a purpose of finding intertextual relations but not when given a purpose of forming one's opinion, external strategy users performed better than non-users in the comprehension of intertextual relations. Also, only when permitted to use external 
strategies, readers with a purpose of relation-finding outperformed readers with a purpose of opinion-forming.

These results can be discussed in terms of what types of external strategy readers used for processing controversial texts. In accordance with Kobayashi (2007b), participants in the present study adjusted their external strategies to fit the reading orientation. That is, more readers with a purpose of relation-finding produced intertextual notes compared to readers with a purpose of opinion-forming, whereas more readers with a purpose of opinion-forming produced personal ideas compared to readers with a purpose of relation-finding. Combined with those who produced quasi-intertextual notes, $17(85 \%)$ readers with a purpose of relation-finding used external strategies for organizing information across the texts. On the other hand, only 7 (35\%) readers with a purpose of opinion-forming produced intertextual and/or quasi-intertextual notes. With regard to this finding, one might argue that both intertextual and quasi-intertextual notes were mere by-products of intertextual processing. In other words, the reading orientation but not the use of external strategies might have influenced the comprehension of relations among controversial texts. However, this is unlikely because there was no significant difference in the comprehension of intertextual relations between the relation-finding and opinion-forming groups when they were not permitted to use external strategies. More plausible explanation is that the use of external strategies for the purpose of relation-finding may have facilitated intertextual processing.

More readers with a purpose of relation-finding also produced discrete summaries compared to readers with a purpose of opinion-forming. Again, this result is consistent with Kobayashi (2007b). One potential reason why readers were more likely to use summarizing strategy when given a purpose of relation-finding is that it may serve the reading purpose. According to the restructuring hypothesis by Britt and Sommer (2004), summarizing a text 
helps readers of multiple texts construct a well-organized and durable mental representation of the text whereby they can easily access to the relevant information of the text stored in memory while reading the subsequent texts. This would be beneficial to connecting ideas across the texts. In addition, summarizing simplifies each text through deleting unimportant or redundant information and abstracting essential statements from the text (Brown \& Day, 1983; Kozminsky \& Graetz, 1986). The simplified external representations of individual texts may make it easier to review in the search of links across the texts (O'Hara, Taylor, Newman, \& Sellen, 2002). As mentioned earlier, students in higher education have some experience of reading controversial texts. It seems likely that participants in the present study knew the effectiveness of summarizing strategy from their experience.

The present study, however, could not test causal relationships between each type of external strategy and outcome performances. To determine what types of external strategy were responsible for better understanding of intertextual relations, future research is needed.

Unexpectedly, the effects of external strategy use on the recall of intratextual arguments were not found. Regardless of reading purpose, external strategy users did not significantly differ from non-users in the number of argumentative units recalled correctly and sentences recalled incorrectly. This result contrasts with prior research on single-text reading that has demonstrated the beneficial effects of external strategy use during reading on the recall of text information (e.g., Brown \& Smiley, 1978; Peverly et al., 2003). One potential reason for the nonsignificant effect of external strategy use is that participants in the present study might have been unskilled users of external strategies. This explanation, however, is inconsistent with the present finding that whey given the purpose of relation-finding, they were capable of using external strategies effectively for intertextual processing. Another more likely explanation is that the discrepancy between the present data 
and prior evidence may be due to the difference in the reading orientation. In most research on single-text reading, participants were oriented to read a text for the purpose of remembering. For example, Brown and Smiley (1978, Experiment $2 \& 3$ ) informed the participants that after reading a text, they would be asked to recall the gist. In a study by Peverly et al. (2003), participants were instructed to study the given text. It may be that they adjusted their external strategies to serve the purpose of remembering, and therefore the use of external strategies enhanced the recall of text information. By contrast, participants in the present study were told to read individual texts for the purpose of either finding intertextual relations or forming one's opinion. Their use of external strategies may not have been fit to enhance the recall of intratextual arguments. This view is consistent with the present finding concerning the interaction effect of external strategy with reading purpose on the comprehension of intertextual relations.

It is important to note that on average participants recalled only $30.9 \%$ argumentative units correctly. The reason for this result cannot be inferred from the present data. There are a lot of possibilities. For example, even students at higher schooling level might be unskilled in processing arguments within a text (see e.g., Grigg, Donahue, \& Dion, 2007; Larson, Britt, \& Larson, 2004). It is also possible that readers' views on a controversial issue might bias intratextual processing (Kardash \& Scholes, 1995; Wiley, 2005). Further work is needed to examine these possibilities.

The present study shed new light on the role of external strategy use in the processing of controversial texts. Nevertheless, some limitations of the present findings should be noted. One limitation is the measure of comprehension of intertextual relations. In the present study, participants' comprehension was assessed using a writing task. Therefore, the comprehension assessed was inseparable from the influence of their writing skills. Future 
research should develop other types of comprehension measure, such as a task that demands to give a schematic presentation of the intertextual relations. Second, not all students at higher schooling level may be capable of adjusting their external strategies to serve the reading purpose. Less-skilled readers are often lacking in the knowledge and skills required to use their reading strategies in a flexible way (Nist \& Holschuh, 2000; Paris, Lipson, \& Wixson, 1983). Possibly this may explain why in a study by Stahl et al. (1996), high school students did not differently use external strategies depending on their reading purposes. Future research should determine whether the interaction effect of external strategy with reading purpose holds for all levels of reading ability. Third, participants in the present study were not permitted to review their notes afterward. Prior research on reading of a single text, however, has shown that external strategy users greatly benefit from later review (Annis, 1979; Kiewra et al., 1989; Slotte \& Lonka, 1999). This may be applicable to cases where external strategies are used for reading controversial texts. To fully understand the role of external strategy use in the processing of controversial texts, future research should examine the effects of later review.

Appendix: Examples of valid and invalid descriptions of intertextual relations in participants' answers

\section{Valid descriptions}

"Although individual writers (Fukui, Ichimura, Mogi, Umeda, Umemura, and Yonemura) express opinion of their own, they agree that there is something wrong with the present educational system in Japan."

“Three writers (Fukui, Mogi, and Umemura) approve the introduction of early English education, whereas the other three (Ichimura, Umeda, and Yonemura) disapprove it."

"With regard to early English education .... Writers who approve it are engaged in 
school education (Fukui and Umemura) or have been familiar with English since their childhood (Mogi), whereas those who disapprove it do not directly concern themselves with school education (Ichimura, Umeda, and Yonemura).”

"The former two (Mogi and Umemura) support the claim that early English education is necessary for learning English, whereas the latter two (Ichimura and Yonemura) oppose it."

"The two (Mogi and Umemura) argue that early English education is effective in the acquisition of English."

“One (Fukui) has a positive view about early English education as international education, whereas the other (Umeda) has a negative view about it."

\section{Invalid descriptions}

“All writers (Fukui, Ichimura, Mogi, Umeda, Umemura, and Yonemura) agree that learning English is necessary for playing an active part in present international society."

"In conclusion, five writers (Fukui, Ichimura, Mogi, Umemura, and Yonemura) are in favor of early English education and one writer (Umeda) is not."

"While these writers (Fukui, Ichimura, Mogi, Umemura, and Yonemura) approve early English education, they point out the issues of the present English education from their respective standpoints."

“The supporters (Mogi and Umemura) focus on English acquisition ability, whereas the opposite fraction (Ichimura and Yonemura) discusses the relation between English and other subjects at elementary school."

"With regard to international education, one writer (Umemura) argues that instruction should be given mainly on pronouncing English sounds correctly .... In contrast, another writer (Umeda) argues that it is important to familiarize learners with spoken English.” 
"The second writer (Ichimura) agrees with the last writer (Yonemura) that in order to make use of English in their own lives, Japanese people should give high priority to developing their abilities of speaking in English rather than leaning grammatical items of English.”

\section{Acknowledgement}

This study was partly supported by a Grant-in-Aid of Scientific Research [Encouragement of Young Scientists (B), No.18730410] from the Japanese Ministry of Education, Science, Sports, and Culture to the author.

\section{References}

Annis, L. F. (1979). Effect of cognitive style and learning passage organization on study technique effectiveness. Journal of Educational Psychology, 71, 620-626.

Benton, S. L., Kiewra, K. A., Whitfill, J. M., \& Dennison, R. (1993). Encoding and external-storage effects on writing processes. Journal of Educational Psychology, 85, 267-280.

Bretzing, B. H., \& Kulhavy, R. W. (1979). Notetaking and depth of processing. Contemporary Educational Psychology, 4, 145-153.

Bridgeman, B., \& Carlson, S. B. (1984). Surveys of academic writing tasks. Written Communication, 1, 247-280.

Britt, M. A., Perfetti, C. A., Sandak, R., \& Rouet, J.-F. (1999). Content integration and source separation in learning from multiple texts. (In S. R. Goldman, A. C. Graesser, \& P. van den Broek (Eds.), Narrative comprehension, causality, and coherence: Essays in honor of Tom Trabasso (pp. 209-233). Mahwah, NJ: Erlbaum.)

Britt, M. A., \& Sommer, J. (2004). Facilitating textual integration with macro-structure focusing tasks. Reading Psychology, 25, 313-339. 
Brown, A. L., \& Day, J. D. (1983). Macrorules for summarizing texts: The development of expertise. Journal of Verbal Learning and Verbal Behavior, 22, 1-14.

Brown, A. L., \& Smiley, S. S. (1978). The development of strategies for studying texts. Child Development, 49, 1076-1088.

Canelos, J., Dwyer, F., Taylor, W., \& Nichols, R. (1984). The notetaking strategy of directed overt activity for improving learning on three types of intellectual tasks. Journal of Instructional Psychology, 11, 139-148.

Cary, M., \& Carlson, R. A. (2001). Distributing working memory resources during problem solving. Journal of Experimental Psychology: Learning, Memory, and Cognition, 27, 836-848.

Caverly, D. C., Orlando, V. P., \& Mullen, J.-A. L. (2000). Textbook study reading. (In R. F. Flippo \& D. C. Caverly (Eds.), Handbook of college reading and study strategy research (pp. 105-147). Hillsdale, NJ: Erlbaum.)

Fisher, J. L., \& Harris, M. B. (1974b). Effect of note-taking preference and type of notes taken on memory. Psychological Reports,35,384-386.

Flower, L., Stein, V., Ackerman, J., Kantz, K., McCormick, K., \& Peck, W. (Eds.) (1990). Reading to write: Exploring a cognitive and social process. (New York: Oxford University Press.)

Grigg, W., Donahue, P., \& Dion, G. (2007). The nation's report card: 12th grade reading and mathematics 2005 (NCES 2007-468). (U.S. Department of Education, National Center for Education Statistics. Washington, D.C.: U.S. Government Printing Office.)

Hegarty, M., \& Steinhoff, K. (1997). Individual differences in use of diagrams as external memory in mechanical reasoning. Learning and Individual Differences, 9, 19-42.

Kardash, C. M., \& Scholes, R. J. (1995). Effects of preexisting beliefs and repeated readings 
on belief change, comprehension, and recall of persuasive text. Contemporary Educational Psychology, 20, 201-221.

Kellogg, R. T. (1988). Attentional overload and writing performance: Effects of rough draft and outline strategies. Journal of Experimental Psychology: Learning, Memory, and Cognition, 14, 355-365.

Kiewra, K. A., DuBois, N. F., Christian, D., Kim, S., \& Lindberg, N. (1989). A more equitable account of the note-taking functions in learning from lecture and from text. Instructional Science, 18, 217-232.

Kiewra, K. A., DuBois, N. F., Christian, D., McShane, A., Meyerhoffer, M., \& Roskelley, D. (1991). Note-taking functions and techniques. Journal of Educational Psychology, 83, 240-245.

Kobayashi, K. (2005). What limits the encoding effect of note-taking?: A meta-analytic examination. Contemporary Educational Psychology, 30, 242-262.

Kobayashi, K. (2007a). The Influence of critical reading orientation on external strategy use during expository text reading. Educational Psychology, 27, 363-375.

Kobayashi, K. (2007b). Fukusu-tekisuto-dokkai-houryaku: Gaiteki-hyousyou no bunseki ni yoru kentou. [Multiple-text reading strategies: An analysis of external representations]. Bulletin of the Faculty of Education, Shizuoka University, Liberal Arts and Social Sciences Series, 56, 269-282.

Kozminsky, E., \& Graetz, N. (1986). First vs second language comprehension: Some evidence from text summarizing. Journal of Research in Reading, 9, 3-21.

Lacroix, N. (1999). Macrostructure construction and organization in the processing of multiple text passages. Instructional Science, 27, 221-233.

Larson, M., Britt, M. A., \& Larson, A. A. (2004). Disfluencies in comprehending 
argumentative texts. Reading Psychology, 25, 205-224.

Lonka, K., Lindblom-Ylanne, S., \& Maury, S. (1994). The effect of study strategies on learning from text. Learning and Instruction, 4, 253-271.

Nist, S. L., \& Holschuh, J. L. (2000). Comprehension strategies at the college level. (In R. F. Flippo \& D. C. Caverly (Eds.), Handbook of college reading and study strategy research (pp. 75-104). Hillsdale, NJ: Erlbaum.)

O'Hara, K., Taylor, A., Newman, W., \& Sellen, A. (2002). Understanding the materiality of writing from multiple sources. International Journal of Human Computer Studies, 56, 269-305.

Paris, S. G., Lipson, M. Y., \& Wixson, K. K. (1983). Becoming a strategic reader. Contemporary Educational Psychology, 8, 293-316.

Peper, R. J.,\& Mayer, R. E. (1986). Generative effects of note-taking during science lectures. Journal of Educational Psychology, 78, 34-38.

Peverly, S. T., Brobst, K. E., Graham, M., \& Shaw, R. (2003). College adults are not good at self-regulation: A study on the relationship of self-regulation, note taking, and test taking. Journal of Educational Psychology, 95, 335-346.

Rouet, J.-F. (2006). The skills of document use: From text comprehension to web-based learning. (Mahwah, NJ: Erlbaum.)

Rouet, J.-F., Britt, M. A., Mason, R. A., \& Perfetti, C. A. (1996). Using multiple sources of evidence to reason about history. Journal of Educational Psychology, 88, 478-493.

Sellen, A. J., \& Harper, R. H. R. (2002). The myth of the paperless office. (Cambridge, MA: MIT Press.)

Slotte, V., \& Lonka, K. (1999). Review and process effects of spontaneous note-taking on text comprehension. Contemporary Educational Psychology, 24, 1-20. 
Stahl, S. A., Hynd, C. R., Britton, B. K., McNish, M. M., \& Bosquet, D. (1996). What happens when students read multiple source documents in history? Reading Research Quarterly, 31, 430-456.

Thornton, N. E., Bohlmeyer, E. M., Dickson, L. A., \& Kulhavy, R. W. (1990). Spontaneous and imposed study tactics in learning prose. Journal of Experimental Education, 58, 111-124.

Todd, W. B., \& Kessler, C. C. (1971). Influence of response mode, sex, reading ability, and level of difficulty on four measures of recall of meaningful written material. Journal of Educational Psychology, 62, 229-234.

Wiley, J. (2005). A fair and balanced look at the news: What affects memory for controversial arguments? Journal of Memory and Language, 53, 95-109. 
Table 1

Brief Summaries of Texts Used in the Study

Fukui, M. (44 years old; supervisor of school board)

English education in elementary schools is significant as international education. In present Japanese society, excessive egalitarianism remains unchanged. At international exchange programs for lower secondary schools, for example, Japanese students rarely express their opinions without obtaining their classmates' consent. It is international education from childhood that shall break down this state. Childhood is ideal for knowing by experience that different ideas and values exist.

Ichimura, S. (73 years old, management consultant)

Consideration should be given to how to teach English, rather than when it is better to start English education. At present, most of English teachers do not use effective teaching methods. The introduction of early English education under such circumstances would be harmful. First of all, it is necessary to re-educate English teachers and improve entrance examinations for upper secondary school or university and English ability tests. 
Table 1 (continued)

Mogi, K. (42 years old; translator)

In my experience, the easiest way of learning a foreign language is to enjoy it from childhood. It is painful for children to start the study of a foreign language, and mainly grammatical items at that, after they enter lower secondary school. They will benefit from earlier English education, even if it is the mere experience of listening to English songs. Promoting English education within a compulsory education system is not a waste of national expenditure.

Umeda, H. (32 years old, office worker)

English education in elementary schools is unnecessary, harmful even. True internationalization means that individuals can confidently express their views on various foreign issues. To do so, they must first learn Japanese language, culture, geography, and history. Under the current educational policy, however, school education does not offer sufficient hours of those subjects. It is the correction of such a state that will lead us to true internationalization. Only being fluent in English is useless. 
Table 1 (continued)

Umemura, M. (40 years old; English teacher of private school and member of the municipal assembly)

In my experience of teaching English, the key to improvement in English language ability is hearing rather than pronunciation. Unless we can follow what a foreigner is saying, the communication will end in one-way traffic. In medical science, it is said that the development of hearing ability stops by the age of nine or so. Therefore, we should train our ears for English before the age. Younger children also surpass older ones in language acquisition ability.

Yonemura, E. (38 years old, housewife)

A large majority of Japanese people need not speak English for their living. Individuals forced by necessity should study English on their own judgments. Under the present circumstances, the introduction of English as a required subject will distress children and teachers in elementary schools. Early English education, even if introduced, should be started in the form of extracurricular activities. Moreover, it is necessary to tell children that one can master English at any age if one is motivated. 
Table 2

Number of Participants Who Produced Each Type of External Representation

\begin{tabular}{ll}
\hline & \multicolumn{2}{c}{ Reading purpose } \\
\cline { 2 - 2 } Type of external representation & Relation-finding Opinion-forming
\end{tabular}

Highlightings

17

18

Discrete summaries

7

2

Personal ideas

4

11

Quasi-intertextual notes

7

4

Miscellany of summaries

2

5

Intertextual notes

11

4 


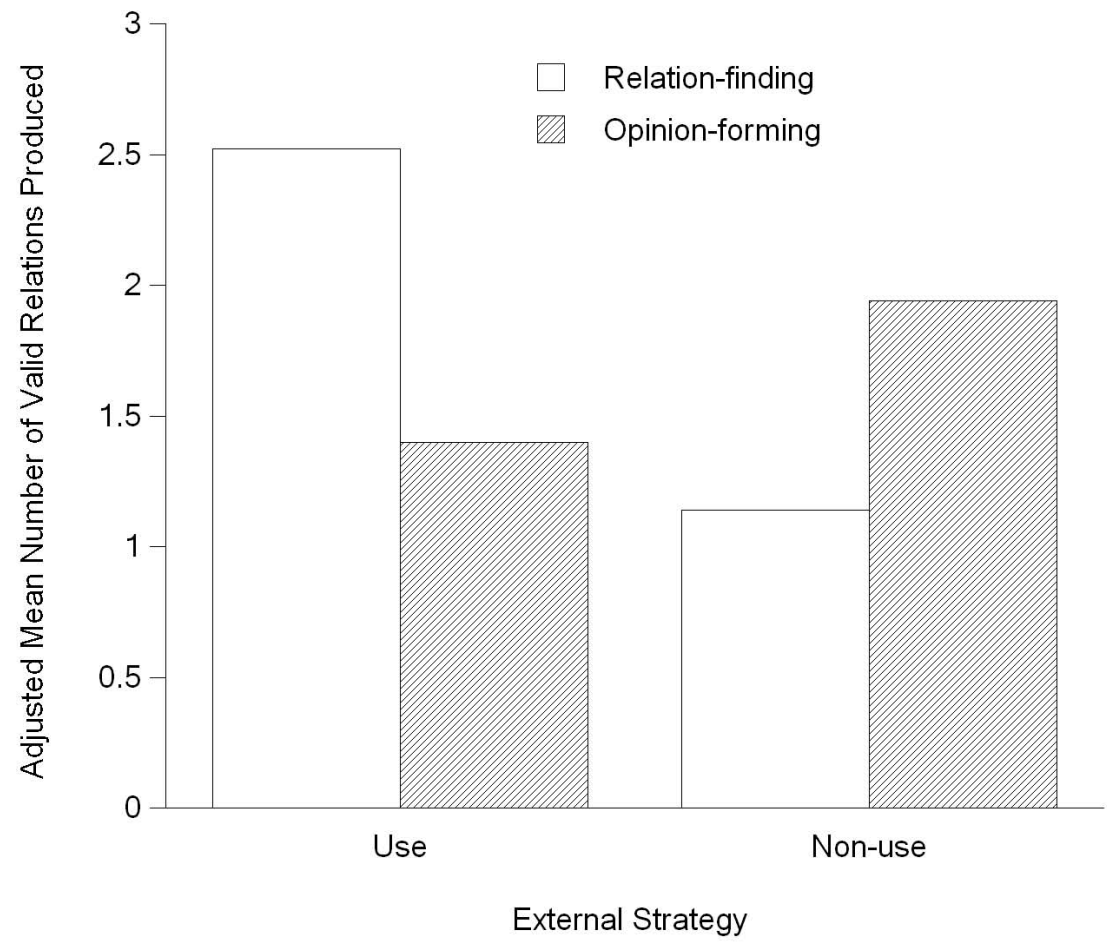

Figure 1. The adjusted mean number of valid relations produced by each group. 